\title{
The Relationship of Critical Thinking Skills and Metacognitive Skills in Middle School Students in Solving Mathematical Problems
}

\author{
Ismail \\ Department of Mathematics \\ Universitas Negeri Surabaya \\ Surabaya, Indonesia \\ ismail@unesa.ac.id
}

\begin{abstract}
Critical thinking skills are one of the most important life skills in the 21st century, because its can improve intelligence in life skills. Critical thinking can improve verbal and analytic skills, enhances creativity, it is important for selfreflection. Metacognition is related to thinking of someone about their own thinking and their ability to use certain learning strategies appropriately. Metacognition involves consciously strategies to control and enhance learning. Critical thinking skills help students to solve mathematical problems. So that the profile of critical thinking skills and their relationship to metacognitive skills in junior high school students in solving the problems of critical thinking in mathematical problems, is very useful to be studied by anyone who has an interest in education. The research subjects were eighth grade junior high school students. Profiles of critical thinking skills and their relationship with metacognitive skills are obtained from in-depth problem-based interviews. The results show that if metacognitive skills of student is good, critical thinking skills student is also good.
\end{abstract}

\section{Keywords—critical thinking skills; metacognitive skills}

\section{INTRODUCTION}

Critical thinking skills are one of the most important life skills in the 21st century, because critical thinking skills can improve intelligence in life skills in addition to other learning skills such as creative thinking, communication skills and collaboration skills (The Partnership for 21st Century Skills , 2009). Critical thinking is one of the skills needed by everyone. According to Huitt (1998) critical thinking is very important in the 21 st century, because this century is an era of information and technology. A person must respond to changes quickly and effectively, thus requiring flexible intellectual skills, the ability to analyze information, and integrate various sources of knowledge to solve problems.

In critical thinking, there are aspects that become critical thinking characteristics, hereinafter referred to as critical thinking indicators. These indicators can be grouped into critical thinking skills. The main critical thinking skills are: interpretation, analysis, evaluation, inference, explanation, and self-regulation. Critical thinking skills are translated into indicators and sub indicators as follows: (1) Interpretation: categorization, decoding, clarifying meaning, (2) Analysis: examining ideas, identifying arguments, analyzing arguments, (3) Evaluation: evaluating claims (statements), judging arguments, (4) Inference: questioning claims, thinking alternatives, drawing conclusions, solving problems, making decisions, (5) Explanation: stating the problem, stating the results, presenting the truth of the procedure, arguing, and (6) Self-regulation: researching yourself, self-correcting. Mathematics is an appropriate discipline to develop critical thinking skills. But teaching mathematics to students does not automatically teach critical thinking to their students. Often teachers do not succeed in teaching critical thinking skills to their students, the teacher teaches the subject matter only. Based on the observations of researchers on teacher mathematics learning in several classes of junior high school students, of the 7 mathematics teachers who came from several different sub-districts in Ponorogo district (Ismail, 2017), showed the following results: and already constructivist, and in learning students are given the opportunity to convey their group's ideas in front of the class. But when students convey their ideas / opinions in front of the teacher class they do not give the opportunity for other groups to argue. Four of the 7 teachers did not give students the opportunity to express their ideas in front of the class. Only 2 out of 7 teachers have developed questions that involve thinking critically and creatively.

The limited trial of critical thinking questions was carried out on 31 eighth grade junior high school students (Ismail, 2017), the questions given consisted of 6 questions with different characteristics. The first question in which there is information that is wrong, the second question that presents contradictory information, the third question is the information that is changed, the fourth question is the problem which is more than one kind, the fifth question contains the wrong conclusions and the sixth questions who meet certain conditions. The limited test results are as follows, the answer to the first question, 4 students can show all the errors and give the correct arguments, 9 students can show one mistake of the three errors in the problem and give the correct argument, 3 students can show one the error of the three errors that are in the problem and giving the wrong argument, 1 student can show one error without argument. The answer to the second 
question, 3 students can show the argument correctly, 13 students give the wrong argument, 14 students give the wrong argument, and 1 students cannot give an argument. The answer to the third question, 2 students can show 3 completely different answers, 9 students can show only 1 correct answer is different, 20 students answered incorrectly. The answer to the fourth question, 4 students can show answers with correct and complete arguments, 25 students answer by trial and error with a little argument, 2 students cannot give an argument. The answer to the fifth question, 2 students give the correct answer with the right argument, and 29 students give the wrong answer accompanied by the wrong argument. The answer to the sixth question, 14 students gave the correct answer with details of 2 students with precise and detailed arguments, 3 students with less detailed arguments, 9 students did not give the argument, while 17 students gave the wrong answer. Based on the results shows that students critical thinking skills in the school are still low, because there are still many students who cannot give the correct argument from the questions asked, even though the question asks students to give arguments.

According to Krulik and Rudnick (1999) to be able to develop students critical thinking skills, the teacher needs to find the right strategy in the learning he does. Critical questions can be asked by the teacher in their students. There are various examples of critical questions for example, Are there other ways? What if ...? What is wrong?

Problems that develop critical thinking skills students have different characteristics compared to ordinary questions. According to Gokhale (in Herman, 2009) the problem of critical thinking is a matter that involves analysis, synthesis, and evaluation of a concept. Meanwhile, according to Langrehr (in Herman, 2009), to train critical thinking students must be encouraged to answer questions relating to the following matters: (1) Determine the consequences of a decision or an event; (2) Identifying the assumptions used in a statement; (3) Formulating problem issues; (4) Finding bias based on different points of view; (5) Reveal the cause of an event; (6) Choosing factors that support a decision.

The issue of critical thinking is a problem that involves analysis, synthesis, and evaluation of a concept. The issue of critical thinking is an open problem or problem, the process is open, the end result is open or the way of further development is open. More specifically, the critical thinking questions used in this study are questions that have the following characteristics: questions that present incorrect information, questions that present contradictory information, problems whose information is changed, questions that resolve more than one kind, questions that contain wrong conclusions, questions that meet certain conditions, questions that contain incomplete information.

According to Lockwood (2003) critical thinking and metacognition skills have strong links, both have a role to develop active participation for all levels of knowledge. Metacognition is related to thinking of someone about their own thinking and their ability to use certain learning strategies appropriately. Metacognition includes metacognitive knowledge and metacognitive skills. Metacognitive skills are the ability of students to choose, use, and monitor learning strategies that are appropriate to their own learning style and the task situation at hand.

Metacognition is aware of what we know and what is not at various levels of cognition. Metacognition also involves consciously strategies to control and improve learning. Critical thinking skills help students to solve problems raised. For example in active learning, if the questions posed by the teacher contain the words "How" and "Why", students realize that they understand the material. With such circumstances they feel better to make valid decisions as to what strategies to learn so they have to answer questions at a higher level of exams.

Based on observations on the learning of 7 teachers in Ponorogo district learning in the classroom found that the reasoning process is still not well developed. In mathematics learning, in particular, it is not high-level reasoning that is taught in classrooms, but rather, quick count skills and memorizing formulas without meaning are prioritized. The reason teachers do not teach high-level reasoning skills is partly because of our national examination model and system. The UN system that is carried out is dominant in information memorization skills only so that the students and also their teachers, avoid high-level reasoning processes.

Based on Lockwood's (2003) opinion, there is a strong relationship between critical thinking and metacognition skills. Both have a role to develop active participation for all levels of knowledge. Critical thinking skills are logical and reflective thinking, which involves an active process of questioning and analyzing information to gain knowledge. Metacognition is seeing the results of students' work. Metacognition is aware of what we know and what is not at various levels of cognition. Metacognition also involves consciously strategies to control and improve learning. Critical thinking skills help students to solve problems raised. For example in active learning, if the questions posed by the teacher contain the words "How" and "Why", students realize that they understand the material. With such circumstances they feel better to make valid decisions as to what strategies to learn so they have to answer questions at a higher level of exams.There is a relationship between someone's critical and metacognitive thinking skills, this is in line with the results of Magno's research (2009) from the Department of Psychology, Faculty of Education and Counseling, De La Salle University, Manila, Philippines. He conducted research on "metacognition influence on critical thinking skills." Hypotheses in his research stated that critical thinking occurs if individuals use their underlying skills namely metacognitive and strategies that increase the likelihood of desired outcomes. His research used two assessments, namely the assessment of metacognitive abilities using the Metacognitive Assessment Inventory (MAI) by Schraw and Dennison (in Magno, 2009), which measured cognition and regulation of cognition, while to measure critical thinking skills used Watson-Glaser Critical Thinking Appraisal ( WGCTA). The test is given to 240 students from different universities in the Philippines. The results showed that metacognition had a positive effect on critical thinking skills.

Based on the description above, the writer conducts research on the profile of critical thinking skills and 
metacognitive skills of junior high school students in solving critical thinking problems in mathematical problems.

\section{MATERIALS AND MethodS}

Based on the purpose of the study, namely obtaining a description of students' critical thinking skills in relation to the metacognitive skills of junior high school students in solving gender critical thinking problems based on gender. To achieve this, qualitative research is used. A qualitative research approach is used with the aim of understanding the phenomenon of what is experienced by the research subject holistically in a specific natural context and observing what is behind the symptoms.

\section{A. Subject}

This research was carried out in eight grade junior high school students were chosen with consideration, the first student is assumed to be at the formal level, so that they are able to think more abstractly to produce critical answers, both students at this level have enough knowledge and experience in basic math materials, because they have passed primary school level in which there are materials, such as numbers, geometry structures or algebraic forms, and the three students' level at this level is still a level of primary education, so the results of exploration of this level of critical thinking can be a foundation or guide for the next level of education. Research subjects were selected based on mathematical abilities. The subject of the study was a grade VIII student of junior high school. The next step is interview. Interviews are conducted to find out and explore students' critical and metacognitive thinking skills.

\section{B. Data Collection Instruments and Techniques}

Data collection instruments and techniques in this study are as follows: (a) The main instruments in this study are the researchers themselves, (b) the question of critical thinking is aimed at students to know the ability to think critically in solving the problem. These questions are problem solving problems, and (c) Interview Guidelines, interviews conducted in this study are task-based interviews, which are carried out by means of the subject being given a written assignment and given time to complete it. After that, the subject was interviewed based on the work already done without showing the answer to the previous assignment. At that time, observations were made by directly making notes to get data about critical thinking skills and students' metacognitive skills. The purpose of the interview is to investigate the process of metacognition and the critical thinking process of students conducted by the subject of research in solving the problems of critical thinking of mathematical problems. Through interviews is expected to explore and express students' critical thinking skills and metacognitive skills in solving critical thinking problems.

\section{RESULTS AND DISCUSSIONS}

Critical thinking test results and interviews with students are as follows:

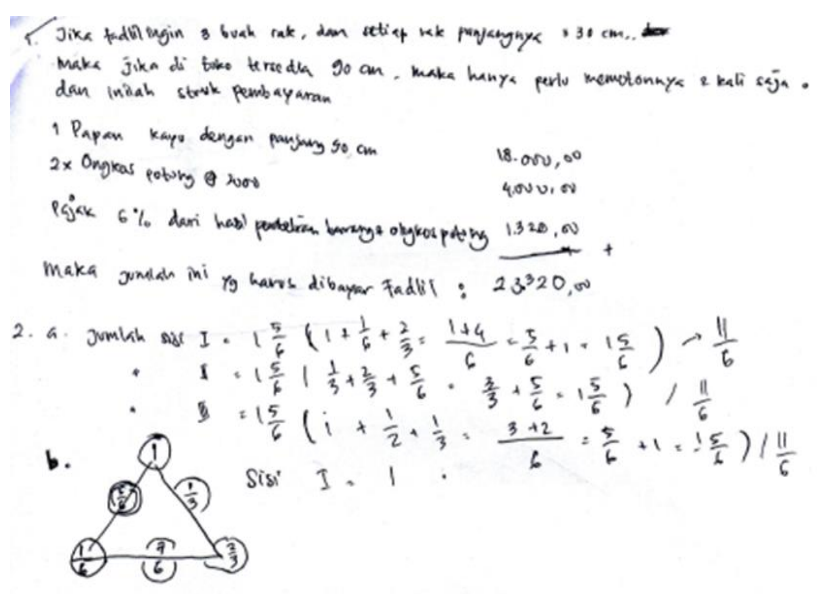

Fig 1. The Results of the Subjects' Test

The results of the critical thinking test were obtained as follows, out of the 6 questions raised 5 questions were answered by students. Three questions were answered correctly accompanied by correct reasoning, while two questions were answered but the reasoning was incorrect. One question is not answered because it feels less time. Search through interviews is conducted to determine students 'metacognitive skills and students' critical thinking skills

The conclusion of the interview excerpt is as follows:

\section{A. Results Relating to Critical Thinking Skills}

Skills Students interpretation appears marked by the following sub-indicators

- Categorization: marked by students can express the meaning and meaning of various data / information in the problem, for example when asked to find an error in the problem, students can explain in detail the information contained in the problem.

- Decode: marked with students being able to read the problem and try to express what is known and asked about the proposed problem. In problem no. 1 student can express what is wrong in the problem and how to find answers to the questions.

- Students' analysis skills appear marked by the following sub-indicators Checking ideas: marked with students can retell arguments related to problems in problem 1 why the data in the problem is wrong, so students can show the wrong facts on the problem.

- Identify arguments: marked with students can express arguments related to the existence of incorrect data on the problem. For example in problem 1 it is stated that the cost error is deducted from the problem, because the interpretation of cutting the board into three equal parts is enough to be cut in two places instead of three places.

- Analyzing arguments: marked with students can state the arguments or basics made in making a conclusion. For example, the student mentioned that the calculation number 
stated on the payment receipt was wrong because of the wrong interpretation of the data on the problem.

Evaluations Skills appears marked by the following sub indicators

- Assessing arguments: marked with students can state confidently with the arguments related to problem 1 and express confidence in the conclusions made

The skills of student inference appear marked by the following sub-indicators

- Draw conclusions: marked with students can express conclusions that occur remembering what is known in the problem / problem. Students can conclude that the data in problem 1 is wrong based on the statements contained in the problem which results in subsequent calculations of the problem being wrong.

- Solve problems: marked with students can mention additional information needed to solve the problem. In solving the problem 2 students know that there is contradictory information on the problem, and to solve the problem additional information is needed so that the statement on the problem becomes correct. In this case students can replace wrong information and add it with new information so that the statement becomes correct.

Students' explanatory skills appear marked by the following sub-indicators

- State the problem: marked with students can explain and relate the results of the analysis. In solving problems 1,2 and 3 students can explain errors in the problem or the wrong information on the problem and based on the results of the analysis students can link one statement with another statement on the problem, so that it can give the correct conclusion.

- Present the correctness of the procedure: marked with students can explain the steps to get an answer. Students can explain the steps to get the right conclusion starting with reading the problem from beginning to end then checking one by one the information contained in the question is it correct and if it is sure to just make calculations so that based on the results of the calculations just make a conclusion.

- Putting an argument: marked with students can explain the reason for the answer. In solving the problems proposed by students can explain the arguments or reasons most of the arguments are correct. Submitted correctly even though there are some inappropriate arguments.

Skills Students interpretation appears marked by the following sub-indicators

- Categorization: marked by students can express the meaning and meaning of various data / information in the problem, for example when asked to find an error in the problem, students can explain in detail the information contained in the problem.
Student self-regulation skills appear marked by the following sub indicators

- Self-correcting: marked by students being able to review what was done before making a final decision. In solving the proposed problem, almost all questions are carried out with the same steps and always review many times before arriving at the final conclusion. Students mention that if necessary, three times review, except when working on the last problem because the time is up.

\section{B. Results Relating to Metacognitive Skills}

Students' predictive skills appear marked by the following sub-indicators

- Select relevant information needed to solve the problem. To complete the first 3 types of questions that are proposed students can choose the information needed to solve the problem, from some information on the problem students can sort out the correct information and the wrong information. - Reread the question to understand the problem. Students always read questions many times starting from beginning to end for each question.

- Make an illustration related to the problem. For answers to questions 1 and 6 students make illustrations in the form of pictures to clarify and help solve problems, but for answers 2,3 , and 5 do not make illustrations in the form of pictures.

- Separating information needed to solve problems. Students can mostly mention the information needed, but find it difficult for questions 4 and 6.

- Write / express in your own words what must be known first related to the problem. Students cannot write on the answer sheet explicitly what should be known about the problem, but at the time of the interview can be explained clearly.

Student planning skills appear marked by the following sub-indicators

- Selecting data / numbers that are relevant to problem solving. Students can write numbers related to problem solving.

- Choose the calculations that will be needed to solve the problem and estimate possible outcomes. Students can choose count operations related to problems such as number 1 related to operations to count integers and fractions, questions 2,5 and 6 related to fraction count operations.

- Choose relevant stages for problem solving. Students can explain the steps starting from the beginning to the expected final conclusion.

- Select relevant materials for problem solving. Students can choose related material, for example in questions 1, 2, 3, 5, and 6 related to integer, or fraction operations, or including both. 
Monitoring skills appear marked by the following subindicators

- Correct / check in counting. Students always check every time they do calculations even if they are not sure about changing the existing answer.

Utilizing records related to problems

- Re-check calculations. Students always double-check every time they do calculations even up to three times and if they are unsure change the existing answer with a new answer.

- Check results. In some questions at the beginning the final results are always checked but towards the end of the test students are not due to time constraints

- Orderly notes. Students are not orderly, so important information on questions is not written.

- Ordered sequences of stages of problem solving. Students are quite orderly in the order of stages in solving problems.

- Monitor the problem solving process that is already running. When the problem solving process always checks the steps and answers written. When having difficulty answering always try to reread the information contained in the problem.

Skills Student evaluation appears marked by the following sub-indicators

- Reflect on what has been done regarding the answers (what went well and how the tasks were completed). Students working on each question always double-check each calculation for the initial problem questions up to three times the check process, students are not easily discouraged when they encounter difficulties and try to replace the answers that they think are not satisfactory.

\section{CONCLUSIONS}

Based on the results above, the researcher draws the following conclusions. Critical thinking skills and subject metacognitive skills are as follows:

\section{A. Subject critical thinking skills}

The subject of interpretation skills appears marked by the emergence of sub-indicators of categorization and decoding; Analysis skills appear marked by the emergence of sub indicators examining ideas, identifying arguments, and analyzing arguments; Evaluation skills are characterized by the emergence of sub indicators assessing arguments; Inference skills are characterized by the emergence of sub-indicators drawing conclusions, solving problems, taking decisions; explanation skills are characterized by the emergence of subindicators stating the problem, expressing the correctness of the procedure, and arguing; Self-regulation skills are characterized by the appearance of self-correcting sub indicators. This shows that critical thinking skills are good.

\section{B. Metacognitive Skills}

Prediction skills: from 10 sub-indicators studied 8 subindicators appear in students, planning skills: from 6 subindicators studied 4 sub-indicators appear in students, monitoring skills: from 15 sub-indicators examined 10 subindicators appear in students, evaluation skills: from 4 subindicators examined 3 sub-indicators appear in students. This shows that the first subject's metacognitive skills are good.

Based on the results of this study indicate that there is a link between students 'critical thinking skills and students' metacognitive skills. Based on the results of limited tests and interviews, it shows that if the metacognitive skills are good, critical thinking skills are also good. Similarly, if the metacognitive skills are not good, critical thinking skills are also not good.

\section{REFERENCES}

[1] A. Desoete, "Evaluating and improving the mathematics teachinglearning process through metacognition," Electronic J. of Res. in Educational Psychology, vol. 5(3), pp. 705-730, 2007.

[2] P.A. Facione, "Critical thinking: What It Is and Why Is Counts," http://www.insightassessment.com/pdf files/what \& why98.pdf. Downloaded at October 28, 2011.

[3] T. Herman, E. Mulyana, and D. Usdiyana, Problem-Based Mathematics Learning to Improve Critical Thinking Ability and Creative Middle School Students. Bandung: Jurusan Pendidikan Matematika FPMIPA Universitas Pendidikan Indonesia Bandung, 2009.

[4] W. Huitt, Critical Thinking: An Overview. Educational Psychology Interactive. Valdosta, GA: Valdosa State University, 1998.

[5] S. Krulik and J.A. Rudnick, Innovative Tasks to Improve Critical and Creative Thinking Skills. Dalam Stiff, Lee V. Curcio, Frances R. (eds). Developing Mathematical reasoning in Grades K-12, Reston: The National Council of teachers of Mathematics, Inc., 1999, pp.138-145.

[6] J.A. Livingston, Metacognition: An Overview. Available: (http://www.gse.buffalo.edu/fas/shuell/cep564/metacog.htm), 1997.

[7] D.F. Lockwood, Metacognition and Critical Thinking for Effective Learning, Professor's Lockwood personal website, 2003. (http://members.shaw.ca/donlockwood/critical.htm) Downloaded at December 30, 2011.

[8] Nurdin Arsyad, Mathematical Learning Model to Grow Metacognition Ability. Desertation Proposal: PPS UNESA - Surabaya, 2004.

[9] S.D. Schafersman, An Introduction to Critical Thinking, Januari 1991. http://www.freeinquiry.com/critical-thinking.html.

[10] The Partnership for 21st Century Skills, 2009. P21 Framework Definitions http://www.21stcenturyskills.org. 